\title{
Aspectos Ecológicos de Atta sexdens piriventris Santschi (Hymenoptera: Formicidae) no Município de Capinzal, Santa Catarina, Brasil
}

\author{
Manuelly Sartori Spier¹, Edson Fernando Spier², Máira Aparecida Dalavéquia ${ }^{3}$ \& Mario Arthur Favretto $\bowtie$
}

1. Autônoma, e-mail: manusartori@yahoo.com.br. 2. Ecoativa Consultoria Ambiental Ltda, e-mail: ecoativaconsultoria@yahoo.com.br, marioarthur.favretto@hotmail.com (Autor para correspondência ${ }^{\varpi}$ ) 3. Universidade do Oeste de Santa Catarina - campus de Joaçaba, e-mail: maira.dalavequia@unoesc.edu.br

\section{EntomoBrasilis 6 (1): 94-96 (2013)}

Resumo. Entre as espécies de formigas economicamente importantes, devido aos danos que muitas vezes causam à agricultura, as mais significativas são as formigas-cortadeiras por possuírem o hábito de cortar e transportar fragmentos vegetais diversos para os seus ninhos subterrâneos. O objetivo deste estudo foi caracterizar alguns aspectos ecológicos de Atta sexdens piriventris Santschi no município de Capinzal, estado de Santa Catarina, Sul do Brasil. O material de origem vegetal transportado pelas formigas apresentou como característica folhas verdes/frescas $57 \%$, folhas secas $23 \%$, pedaços de frutos $7 \%$, sementes $7 \%$ e flores $3 \%$. Já os de origem animal tiveram uma representação de $3 \%$, e eram compostos por pedaços de insetos. A média de distância percorrida pelas formigas em busca do substrato foi de 12,54 m.

Palavras-chaves: Forrageio; Myrmicinae; Ninhos; Substratos.

\section{Ecological Aspects of Atta sexdens piriventris Santschi (Hymenoptera: Formicidae) in the Municipality of Capinzal, Santa Catarina, Brazil}

Abstract. Among the economically important species of ants, due to the damage they often cause the agriculture the most significant are the leafcutting ants because they have the habit of cut and transport various plant fragments to their underground nests. The objective of this study was characterized some ecological aspects of Atta sexdens piriventris Santschi in the municipality of Capinzal, Santa Catarina state, Southern Brazil. The plant material transported by the ants was $57 \%$ of green leaves, $23 \%$ of dried leaves, $7 \%$ of fruits, $7 \%$ of seeds, $3 \%$ of flowers and only $3 \%$ of animal parts, mostly compounds by insect parts. The average distance walked by the ants in search of the substrate was $12.54 \mathrm{~m}$.

Keywords: Foraging; Myrmicinae; Nests; Substrates.

牙: stima-se existir aproximadamente 12.116 espécies de formigas, ocupando diferentes habitats (BoLTon 2012). As formigas-cortadeiras, pertencentes à família Formicidae, subfamília Myrmicinae, tribo Attini, representam um grupo especial de formigas associadas à vegetação, neste grupo encontram-se os gêneros Atta e Acromyrmex. Embora existam outros gêneros, estes assumem pouca importância no forrageamento de plantas cultivadas (GIESEL 2007). Dentre os insetos-praga da agricultura e da silvicultura brasileira, as formigas-cortadeiras destacam-se como os principais agentes de danos devido aos prejuízos que causam pelo fato de atacarem praticamente todas as plantas cultivadas (GonçALVES 1945).

A preocupação com o controle de formigas-cortadeiras é constante em muitos agroecossistemas, estimando-se um consumo nacional de aproximadamente 12.000 toneladas/ano de iscas tóxicas, forma mais comumente utilizada para minimizar efeitos negativos destes insetos (BOARETTO \& ForTI 1997). Cada espécie de formigacortadeira apresenta características próprias de nidificação, comportamento, hábitos de corte de folhas, especificidade de coleta de material, etc. $\mathrm{O}$ desconhecimento desses fatores tem levado vários métodos de controle ao insucesso (Augustin et al. 1999). Levando em consideração a gravidade dos problemas causados pelas formigas-cortadeiras, torna-se muito importante caracterizar alguns aspectos ecológicos destas espécies.

Foram utilizadas duas áreas no município de Capinzal, MeioOeste de Santa Catarina, Sul do Brasil, sendo uma das áreas lavoura e a outra próxima localizada interior de mata, ambas na localidade $27^{\circ} 23^{\prime} 12,38^{\prime \prime}$ S $51^{\circ} 34^{\prime} 59,10$ ”O A área de mata é caracterizada como um remanescente de floresta estacional semidecidual. As áreas foram monitoradas por um período de seis meses a cada 21 dias do mês de outubro de 2007 até o mês de março de 2008 sempre no período diurno com prevalência entre os horários 09:30 h às 10:50 h, tendo por objetivo coletar e identificar as espécies de formigas-cortadeiras ocorrentes nestas áreas, identificar os substratos transportados aos ninhos, verificar a distância percorrida pelas formigas em busca do alimento e caracterizar o tipo do ninho

Os animais foram coletados com auxílio de um aspirador entomológico, posteriormente esses animais foram acondicionados em álcool 70\%. A identificação das espécies foi realizada com o auxílio de chaves de identificação de DELLA-LúcIA (1993), e posteriormente confirmada pelo professor Dr. Benedito C. Lopes da Universidade Federal de Santa Catarina.

Para a observação dos substratos utilizados pelas formigas o esforço amostral foi de 10 minutos por ninho, metodologia proposta por LOPEs (2007) sempre no período diurno, sendo o material diferenciado em vegetal e animal, e para evitar alterações no comportamento das formigas/operárias foi adotada apenas observação visual. Para conhecer a distância percorrida pelas formigas, estas foram acompanhadas em seus deslocamentos dos ninhos até as fontes alimentares e o trajeto percorrido foi então medido. Para a caracterização do tipo de ninho foi observado a 
T sua localização (superficiais ou subterrâneos).

Um total de 45 indivíduos de formigas cortadeiras foi coletado para identificação, todas as formigas coletadas pertenciam à Atta sexdens piriventris Santschi. Estes animais apresentam como características morfológicas três pares de espinhos no dorso do tórax e a superfície dorsal do gáster lisa, não apresentando tubérculos. LoEck et al. (2001) em estudo realizado no Rio Grande do Sul também encontrou apenas esta espécie, confirmando as informações de GonçAlves (1945) referente à distribuição desta formiga para os estados de Santa Catarina e Rio Grande do Sul.

No presente trabalho foi observada a existência de preferências quanto ao substrato transportado pelas formigas cortadeiras, onde $97 \%$ do material era de origem vegetal e $3 \%$ de origem animal. O material de origem vegetal transportado pelas formigas apresentou como característica folhas verdes/frescas $57 \%$, folhas secas $23 \%$, pedaços de frutos $7 \%$, sementes $7 \%$, flores $3 \%$ e 3 insetos (Tabela 1). A preferência por este tipo de substrato (folhas verdes/frescas) pode estar relacionada ao fato deste tipo de substrato apresentar maior concentração de aminoácidos (Della-Lúcia 1993).

Tabela 1. Material coletado por Atta sexdens piriventris e respectiva quantidade durante os meses de outubro de 2007 a março de 2008.

\begin{tabular}{lc}
\hline \multicolumn{1}{c}{ Material Coletado } & Número de exemplares do material \\
\hline Folhas verdes/frescas & 17 \\
\hline Folhas secas & 7 \\
\hline Pedaços de frutos & 2 \\
Flores & 1 \\
Sementes de frutos & 2 \\
Pedaços de insetos & 1 \\
\hline
\end{tabular}

As formigas aqui registradas que apresentavam os ninhos na lavoura percorreram em média 16,83 $\mathrm{m}$ em busca do substrato, enquanto que as formigas que apresentavam seus ninhos no interior da mata a distância média percorrida foi de $8,31 \mathrm{~m}$. Esta distância foi obtida acompanhando o deslocamento das formigas até suas fontes alimentares. Em estudo realizado com Atta vollenweideri Forel em Barra do Quaraí, Rio Grande do Sul (Simas et al. 2002), os caminhos estabelecidos por estas formigas, partindo do ninho e afastando-se dele em direção aos locais de coleta de folhas, bifurcando e diversificando-se, alcançaram mais de $100 \mathrm{~m}$ de distância do ninho.

Nas duas áreas de estudo foram encontrados ninhos subterrâneos, que apresentam como característica terra solta na superfície do solo e composto por diversos olheiros. Os resultados do presente estudo corroboram DelLa-Lúcia et al. (2001), onde a autora descreve os ninhos, sendo os olheiros como pequenos orifícios por onde as formigas saem em busca de seus recursos e o utilizam para a retirada da terra escavada do interior do ninho durante a sua construção, e alguns olheiros cumprem a função de ventilação da colônia.

Os ninhos observados no presente trabalho também foram semelhantes aos descritos por MARICONI (1970), os quais apresentam na superfície do solo um acúmulo de terra solta, chamado de murundu, que é o produto das escavações subterrâneas. Nos meses que antecedem a revoada o depósito de terra na superfície é mais intenso e praticamente não ocorrendo nos períodos de chuva (dezembro a abril). O tipo de murundu varia de acordo com a espécie. De baixo da superfície são encontrados canais, galerias ou túneis que ligam as câmaras ou que possibilitam o acesso à superfície. Os canais podem ser classificados em canais de aterro, ventilação e alimentação.

Nas duas áreas de estudo (mata nativa e lavoura) A. sexdens piriventris foi a única espécie de formiga-cortadeira presente, não havendo assim diferenças entre espécies, tipo de ninho e substrato transportado nas duas áreas estudadas. A correta identificação da espécie Atta sexdens piriventris bem como os substratos carregados e identificados poderão auxiliar na determinação de métodos de controle a serem utlizados a campo. A falta de informação sobre estes animais, os métodos de controle inadequados aliados ao desconhecimento por parte dos agricultores acabam ocasionando problemas secundários como, o não carregamento das iscas e até mesmo impactos ambientais, entre eles o excesso de veneno no solo.

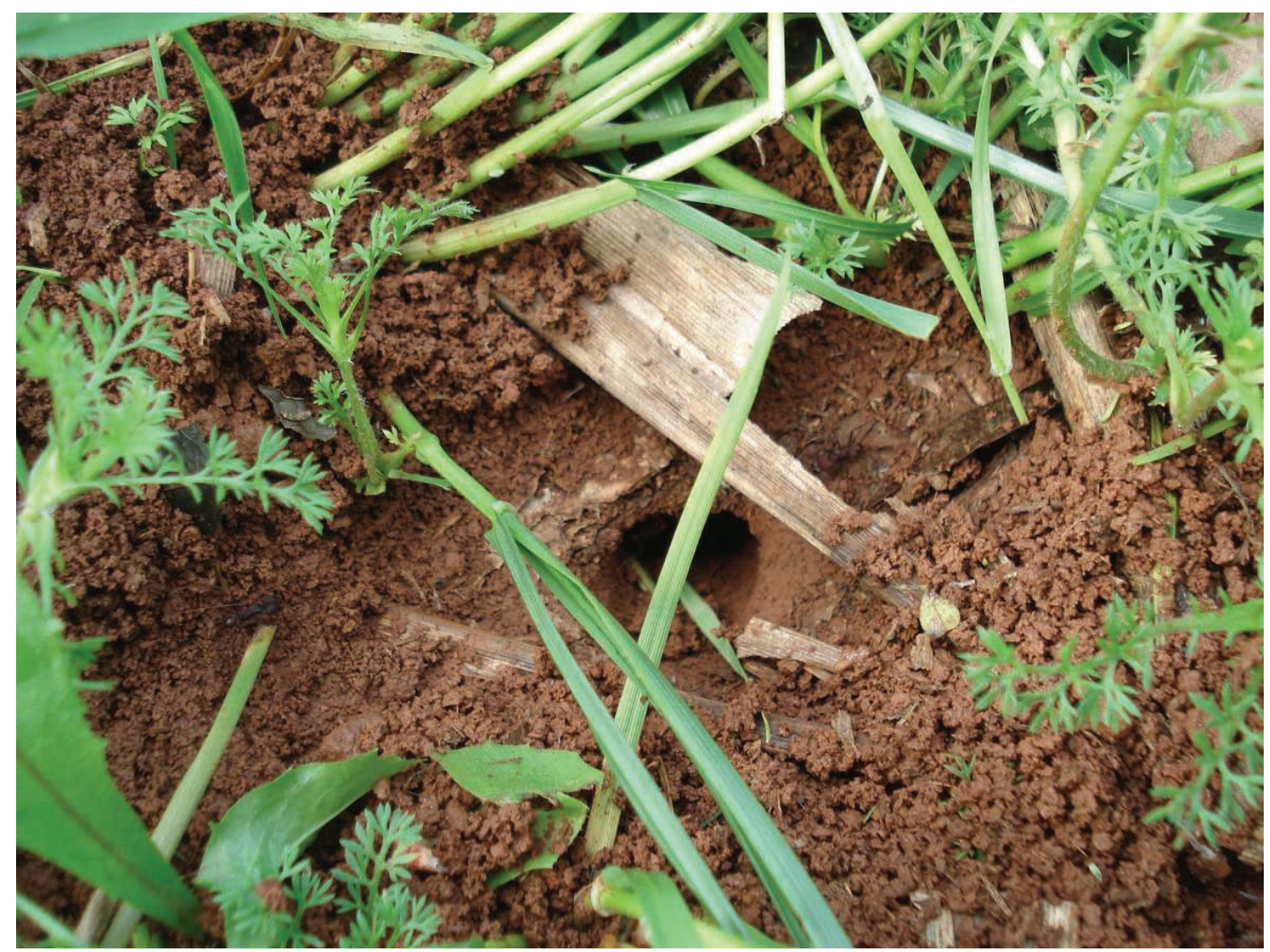

Figura 1. Olheiro de ninho de Atta sexdens piriventris no Município de Capinzal, Estado de Santa Catarina. Foto: E.F. Spier. 


\section{AGRADECIMENTOS}

Os autores são gratos aos revisores do periódico EntomoBrasilis por todas as críticas e sugestões.

\section{REFERÊNCIAS}

Augustin, E., A.E. Loeck, G. Storch, D.D. Grützmacher, A.P.S. Afonso \& L.G. Gusmão, 1999. Identificação de formigas cortadeiras do gênero Acromyrmex (Hymenoptera: Formicidae) através de isoenzimas. Revista Brasileira de Agrociência, 5: 217-220.

Boaretto, M.A.C. \& L.C. Forti. 1997. Perspectivas no controle de formigas cortadeiras. Série Técnica IPEF, 11: 31 - 46.

Bolton, B., 2012. Taxonomic History. Antweb. Disponível em: $<$ http://www.antweb.org/description.do?name=formicidae \&rank=family\&project=allantwebants $>$ [01/08/2012]

Della-Lúcia, C.M.T., A.C. Lima \& A.N. Silva, 2001. Formigas Cortadeiras: Biologia e controle. Viçosa: UFV (Boletim de Extensão, 44), 28p.

Della-Lúcia, C.M.T. 1993. As Formigas Cortadeiras. Viçosa: Ed. Folha de Viçosa. 262p.

Giesel, A., 2007. Preparados Homeopáticos, Iscas Fitoterápicas, Conhecimento Popular e Estudo do Comportamento para o Manejo das Formigas Cortadeiras no Planalto Serrano
Catarinense. Dissertação (Mestrado em Agronomia) Universidade do Estado de Santa Catarina. 94p.

Gonçalves, R.C., 1945. Saúvas do Sul e Centro do Brasil. Rio de Janeiro: Ministério da Agricultura do Brasil. (Boletim Fitossanitário, 2: 183-218.

Loeck, A.E., D.D. Grützmacher \& G. Storch, 2001. Distribuição Geográfica de Atta sexdens piriventris (Santschi, 1919) nas principais regiões agropecuárias do estado do Rio Grande do Sul. Revista Brasileira de Agrociências, 7: 54-57.

Lopes, C.B., 2007. Ecologia do forrageio por Cyphomyrmex morschi Emery (Hymenoptera, Formicidae) em vegetação de restinga do Sul do Brasil. Revista Brasileira de Zoologia, 24: 52-56.

Mariconi, F.A.M., 1970. As saúvas. São Paulo, Agronômica Ceres. $167 \mathrm{p}$.

Simas, R.V., C.C. Costa \& A.C. Simas, 2002. Características Externas do Ninho de Atta vollenweideri Forel, 1893 (Hymenoptera: Formicidae). Uruguaiana, 9: 69-75.

\section{Recebido em: 16/o5/2012}

Aceito em: 11/o8/2012

\section{Como citar este artigo:}

Spier, M.S., E.F. Spier, M.A. Dalavéquia \& M.A. Favretto, 2013. Aspectos Ecológicos de Atta sexdens piriventris Santschi (Hymenoptera: Formicidae) no Município de Capinzal, Santa Catarina, Brasil. EntomoBrasilis, 6(1): 94-96.

Acessível em: http://www.periodico.ebras.bio.br/ojs/index.php/ebras/article/view/248. doi:10.12741/ebrasilis.v6i1.248
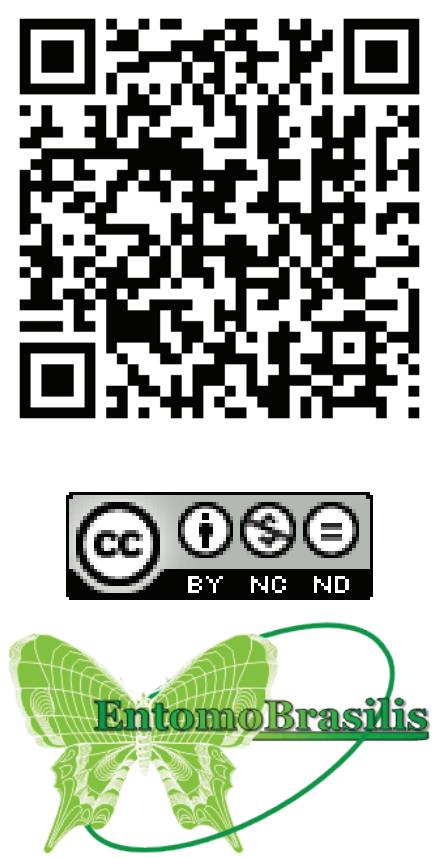